\title{
Waste Tire Heat Treatment to Prepare Sulfur Self-Doped Char: Operando Insight into Activation Mechanisms Based on the Char Structures Evolution
}

\author{
Qiangqiang Ren ${ }^{1}$, Song $\mathrm{Hu}^{1}{ }^{1}$, Qingwei $\mathrm{Hu}^{2}{ }^{2}$, Qing Li ${ }^{3}$, Limo He ${ }^{1}$, Zhiwen Lei ${ }^{1}$, Sheng Su ${ }^{1}$, Yi Wang ${ }^{1}$, \\ Long Jiang $^{1, *}$ and Jun Xiang ${ }^{1}$ (iD)
}

1 State Key Laboratory of Coal Combustion, School of Energy and Power Engineering, Huazhong University of Science and Technology, Wuhan 430074, China; renqiangqiang0301@163.com (Q.R.); husong@hust.edu.cn (S.H.); limo_615@163.com (L.H.); m15180071749@163.com (Z.L.); susheng_2003@163.com (S.S.); alenwang@hust.edu.cn (Y.W.); xiangjun@mail.hust.edu.cn (J.X.)

2 Shouyang Mountain Power Plant, Datang Corporation Ltd., Luoyang 471900, China; hqw2212@outlook.com

3 School of Materials Science and Engineering, Huazhong University of Science and Technology, Wuhan 430074, China; qing_li@hust.edu.cn

* Correspondence: jianglong@hust.edu.cn; Tel.: +86-27-8754-2417

check for updates

Citation: Ren, Q.; Hu, S.; Hu, Q.; Li, Q.; He, L.; Lei, Z.; Su, S.; Wang, Y.; Jiang, L.; Xiang, J. Waste Tire Heat Treatment to Prepare Sulfur Self-Doped Char: Operando Insight into Activation Mechanisms Based on the Char Structures Evolution. Processes 2021, 9, 1622. https:// doi.org/10.3390/pr9091622

Academic Editor: Haoran Jiang

Received: 10 August 2021

Accepted: 6 September 2021

Published: 9 September 2021

Publisher's Note: MDPI stays neutral with regard to jurisdictional claims in published maps and institutional affiliations.

Copyright: (c) 2021 by the authors. Licensee MDPI, Basel, Switzerland. This article is an open access article distributed under the terms and conditions of the Creative Commons Attribution (CC BY) license (https:// creativecommons.org/licenses/by/ $4.0 /)$.

\begin{abstract}
Waste tire (WT) can be heat-treated to be high-quality sulfur self-doped char via pyrolysis and $\mathrm{K}_{2} \mathrm{FeO}_{4}$-assisted activation processes. This work aimed at further studying the activation mechanisms based on the char structures evolution by operando experimental method. Activation treatment process (from $50{ }^{\circ} \mathrm{C}$ to $800^{\circ} \mathrm{C}$ and then held for $3 \mathrm{~h}$ ) was divided into six typical stages (S1S6) and consisted of carbonization process (S1-S4) and effective activation process (S4-S6). During the carbonization process, the specific capacitance only increased from $0.2 \mathrm{~F} / \mathrm{g}$ to $12.4 \mathrm{~F} / \mathrm{g}$, aromatic ring systems and alkyl-aryl C-C bonds generated, $\mathrm{S} 2 \mathrm{p}_{3 / 2}$ (sulphide bridge) was mainly gradually consumed. During the effective activation process, the specific capacitance hugely increased from $12.4 \mathrm{~F} / \mathrm{g}$ to $112.5 \mathrm{~F} / \mathrm{g}$, aromatic ring systems and alkyl-aryl C-C bonds turned to ordered graphitic char. The pores massively generated from S4 to S5, while micropores partly formed to larger and mesopores+macropores fractionally converting to smaller from S5 to S6. Besides, both S $2 \mathrm{p}_{3 / 2}$ and S $2 p_{5 / 2}$ (sulphone bridge) were enriched after S5. Furthermore, the key structural parameters for huge improvement of specific capacitance were found and it further revealed that mesopores+macropores possessed stronger promotion effect than micropores and $S 2 p_{3 / 2}$ was more beneficial than $S 2 p_{5 / 2}$.
\end{abstract}

Keywords: waste tire; sulfur; char; activation; structure; specific capacitance

\section{Introduction}

Tire, plays an essential role in transportation and its production amount has been sharply rising, would even hit 2.5 billion pieces in 2020 over the world amazingly [1]. As a result, huge quantities of WTs are produced with tires constantly upgrading, causing serious pollutions to the environment since they cannot be naturally degraded [2,3]. Pyrolysis has been regarded as a promising technology to treat WTs as a result of it can be efficiently converted to high-valued oils by pyrolysis [4-7]. Unfortunately, large amounts of low-quality waste tire chars (WTCs) would generate via pyrolysis operation and their proportions commonly exceed $40 \mathrm{wt} \%$ compared with mass of WTs [8]. Driven by great production capacity and economic value of WTs dispose, upgrading WTCs based on specific applications is significantly worth to carry out broad studies [9-12].

Nowadays, pyrolytic WTCs are mainly used to produce carbon blacks $[13,14]$. However, it would take many times and costs to conduct desulfurization operations, because the contents of intrinsic sulfur in WTCs are usually high over $2 \mathrm{wt} \%[8,15]$. As a result, it would be much promising to easily treat WTCs and achieve higher-valued applications. Expectedly, it has been proved by us that high content of intrinsic sulfur can effectively 
dope in the char structure and promote its specific capacitance by activation treatment process with assistance of $\mathrm{K}_{2} \mathrm{FeO}_{4}[16,17]$. However, in our previous works, we mainly focused on the effects of pyrolysis temperature [16] and activation conditions (activation temperature and $\mathrm{K}_{2} \mathrm{FeO}_{4}$ additive ratio) [17] on the final products. Besides, so far, there have been many published works studying the carbon material structures and specific capacitance performances [18-20]. However, just like us, they all paid too much attention to the products and ignored the activation treatment process. Importantly, during the activation treatment process, the carbon material structures would evolve to be finally shown to researchers. Investigating into the activation treatment process based on the evolution of char structure could benefit to further understand the activation mechanisms, and make guidance to activation operations.

In addition, the specific capacitance performances of carbon materials are strongly related with their physical and chemical structures [21,22]. Moreover, the structures would strongly be affected by activation treatment process based on our previous studies $[16,17]$. As for physical structures, textural properties are basically involved, and they consist of specific surface area, pore volume, and average pore diameter [23-25]. In addition, pores are together composed by micropores, mesopores, and macropores [26]. The chemical structures can be jointly described by the carbon skeleton structure and heteroatoms doping structures. Complexly, doped sulfur is composed by sulphide bridge (-C-S-C-, S 2 $\mathrm{p}_{3 / 2}$ ) and sulphone bridge (-C-SOx-C- $\left.(x=2-4), S 2 p_{5 / 2}\right)$ respectively $[16,17,27]$. Therefore, the structural parameters are multitudinous, which jointly decide the specific capacitance performances of product carbon materials $[12,19,20]$. However, the correlations between specific capacitance and physical/chemical structures during activation treatment process are not clear yet. Studying them can strongly make significant guidance to further promote specific capacitance.

In this work, the $\mathrm{K}_{2} \mathrm{FeO}_{4}$-assisted activation treatment process of WTC was divided into six typical stages based on the thermogravimetric analyzer (TGA) result. Then, WTC was heat-treated at the detailed reaction conditions of those stages with a horizontal tube furnace respectively. The yields of products and activated waste tire chars (AWTCs) with corresponding specific capacitances were calculated. Besides, the physical and chemical structures of chars were systematically analyzed by $\mathrm{N}_{2}$ adsorption-desorption analyzer, Raman spectrometer (Raman), element analyzer (EA), and X-ray photoelectron spectroscopy (XPS). The activation mechanisms based on the structural evolution of WTC were thus revealed. The correlations between specific capacitance and multitudinous physical/chemical structural parameters were firstly revealed systematically.

\section{Materials and Methods}

\subsection{Activation Treatment Experiments}

The raw material (WT) was purchased from Sichuan Huayi Rubber Company and cut into about 40 mesh. The proximate and element analysis results of WT were shown in our previous work [16]. Firstly, heating WT (ca. $10 \mathrm{~g}$ ) to $400{ }^{\circ} \mathrm{C}$ with a heating rate of $5{ }^{\circ} \mathrm{C} / \mathrm{min}$ and then holding for $1 \mathrm{~h}$ under $0.5 \mathrm{~L} / \mathrm{min} \mathrm{N}_{2}$ flow in a horizontal tube furnace, the acquired WTC was named WTC400 and used as the reactant for subsequent activation. The selection of pyrolysis temperature at $400{ }^{\circ} \mathrm{C}$ was based on our published works $[15,16]$, and it can benefit for the larger specific capacitance of activated char.

$0.5 \mathrm{~g}$ WTC400 was mixed with $1.5 \mathrm{~g} \mathrm{~K}_{2} \mathrm{FeO}_{4}$ (AR, CAS: 39469-86-8, MACKIN), and $30 \mathrm{~mL}$ deionized water was then added to form homogeneous mixture. Thereafter, the mixture was moved to a rotary shaker at $30 \mathrm{r} / \mathrm{min}$ for $24 \mathrm{~h}$, which was then well dried at $105{ }^{\circ} \mathrm{C}$ for $48 \mathrm{~h}$ and ground fully. The powder mixture of WTC400 and activation agent was put into a TGA (STA8000, PerkinElemer Company, Waltham, MA, USA) to be heated from $50{ }^{\circ} \mathrm{C}$ to $800{ }^{\circ} \mathrm{C}$ with $5{ }^{\circ} \mathrm{C} / \mathrm{min}$ and then held for $3 \mathrm{~h}$, thus the mass loss information was recorded. The selection of activation conditions was based on the published works $[16,17]$, and they can assist in achievement of the relatively high yield and large specific capacitance. According to the mass loss characteristics, the activation 
treatment process can be divided into six typical stages (S1-S6) and their reaction conditions can be directly acquired. Following, the homogeneous mixtures were activated at the detailed reaction conditions above in a horizontal tube furnace respectively. The collected products were repeatedly washed by $1 \mathrm{M} \mathrm{HCl}$ solution and deionized water until pH of filtrates were neural, then the samples were dried at $105^{\circ} \mathrm{C}$ for $24 \mathrm{~h}$ to collect AWTCs that were weighed to calculate the yields of AWTCs as shown in Equation (1):

$$
\text { Yield }_{\text {AWTC }}(\%)=\frac{M_{\text {AWTC }}}{M_{\text {WTC400 }}} \times 100 \%
$$

where $\mathrm{M}_{\text {AWTC }}$ was mass of AWTC, $\mathrm{M}_{\text {WTC400 }}$ represented mass of WTC400 and it was $0.5 \mathrm{~g}$ in the activation experiments.

\subsection{Physical and Chemical Properties Characterization}

Before all the characterizations, AWTCs were mixed adequately to ensure their homogenization. AWTCs at six typical stages were loaded on the nickel foam sheet to prepare working electrodes respectively and measured as guided by our previous work [16]. The working electrodes were subsequently analyzed in a three-electrode system with an electrochemical station (CHI 660E, Chenhua Company, Shanghai, China) using galvanostatic charge/discharge (GCD) method. The three-electrode system was composed by a working electrode, reference electrode $(\mathrm{Hg} / \mathrm{HgO})$, counter electrode (platinum sheet), and electrolyte (6 $\mathrm{M} \mathrm{KOH}$ solution). After the working electrodes were soaked in the electrolyte for $5 \mathrm{~min}$ to ensure thoroughly wetting. The GCD measurements were then finished at a current density of $1 \mathrm{~A} / \mathrm{g}$, and voltage windows were set as $-1 \sim 0 \mathrm{~V}$, the specific capacitances were thus calculated as shown in Equation (2):

$$
\mathrm{C}=\frac{\mathrm{I} \Delta \mathrm{t}}{\mathrm{m} \Delta \mathrm{V}}
$$

where I was charge/discharge current, $\mathrm{m}$ was mass of active material, $\Delta \mathrm{V}$ was voltage change during charge/discharge process, $\Delta \mathrm{t}$ was charge/discharge time corresponding to the voltage change. Here, I was set as $4 \mathrm{~mA}$, $\mathrm{m}$ was $4 \mathrm{mg}$.

The textural properties were determined via a $\mathrm{N}_{2}$ adsorption-desorption analyzer (BK100A, JWGB Company, Beijing, China). During this measurement, AWTCs were firstly heat-treated at $300{ }^{\circ} \mathrm{C}$ for $2 \mathrm{~h}$ to fully desorb the gases that were absorbed in the surface of chars, they were then soaked in the liquid nitrogen to maintain $77 \mathrm{~K}$ to finish the $\mathrm{N}_{2}$ adsorption and desorption processes automatically. The carbon skeleton structures were analyzed by Raman (DXR2, Thermo Fisher Company, Waltham, MA, USA) with a laser excitation wavelength of $532 \mathrm{~nm}$. AWTCs were all carefully observed by the appendant microscope. Then five random areas were selected to collect Raman spectrums and they were averaged to conduct subsequent analysis. The contents and chemical states of element carbon and sulfur were deeply investigated by EA (Vario Micro cube, Elementar Company, Frankfurt, Germany) and X-ray photoelectron spectroscopy (XPS, ESCALAB 250XI, Thermo Fisher Company, Waltham, MA, USA) respectively. During EA measurements, the samples were fully burnt, and element carbon and sulfur would exist in the forms of $\mathrm{CO}_{2}$ and $\mathrm{SO}_{2}$, which would be detected via a thermal conductivity detector to obtain the corresponding contents. Every sample was tested repeatedly two times and they were averaged to represent the element contents in AWTCs. As for XPS measurements, Al K $\alpha$ was selected as X-ray resource and C 1 s and S 2p spectrums of AWTCs were acquired to be analyzed.

\section{Results and Discussions}

\subsection{Activation Treatment Process of WTC}

The activation experiment of temperature from $50{ }^{\circ} \mathrm{C}$ to $800{ }^{\circ} \mathrm{C}$ with a heating rate being $5{ }^{\circ} \mathrm{C} / \mathrm{min}$ and retention time being $180 \mathrm{~min}$ at $800{ }^{\circ} \mathrm{C}$ was firstly performed in a TGA to analyze the activation treatment process of WTC400 with $\mathrm{K}_{2} \mathrm{FeO}_{4}$. The mass loss information was recorded and shown in Figure 1. It could be clearly seen that the 
activation treatment process takes on different characteristics and it can be composed by five processes. Hence, the activation treatment process can be divided into six stages and the mass loss rates keep relatively stable between two adjacent stages, whose reaction conditions are systematically listed in the inset table in Figure 1. In order to deeply study the activation treatment process, the homogeneous mixtures of WTC400 and activation agent were heat-treated at the detailed reaction conditions in a horizontal tube furnace respectively, and the products and AWTCs at six typical stages were acquired. The product yields of six stages in TGA and furnace were calculated and listed in Table 1, they are $100.0 \% / 100.0 \%, 96.7 \% / 95.0 \%, 85.1 \% / 82.3 \%, 80.2 \% / 81.7 \%, 55.8 \% / 61.5 \%$, and $40.9 \% / 43.7 \%$ respectively. It is obviously shown that the product yields in furnace are very close to those in TGA, illustrating these products in furnace can effectively reflect the states of samples during activation treatment process and the experiments are reliable. Thus, the samples obtained by furnace can be reasonably used to study the physical/chemical structural evolution of the char.

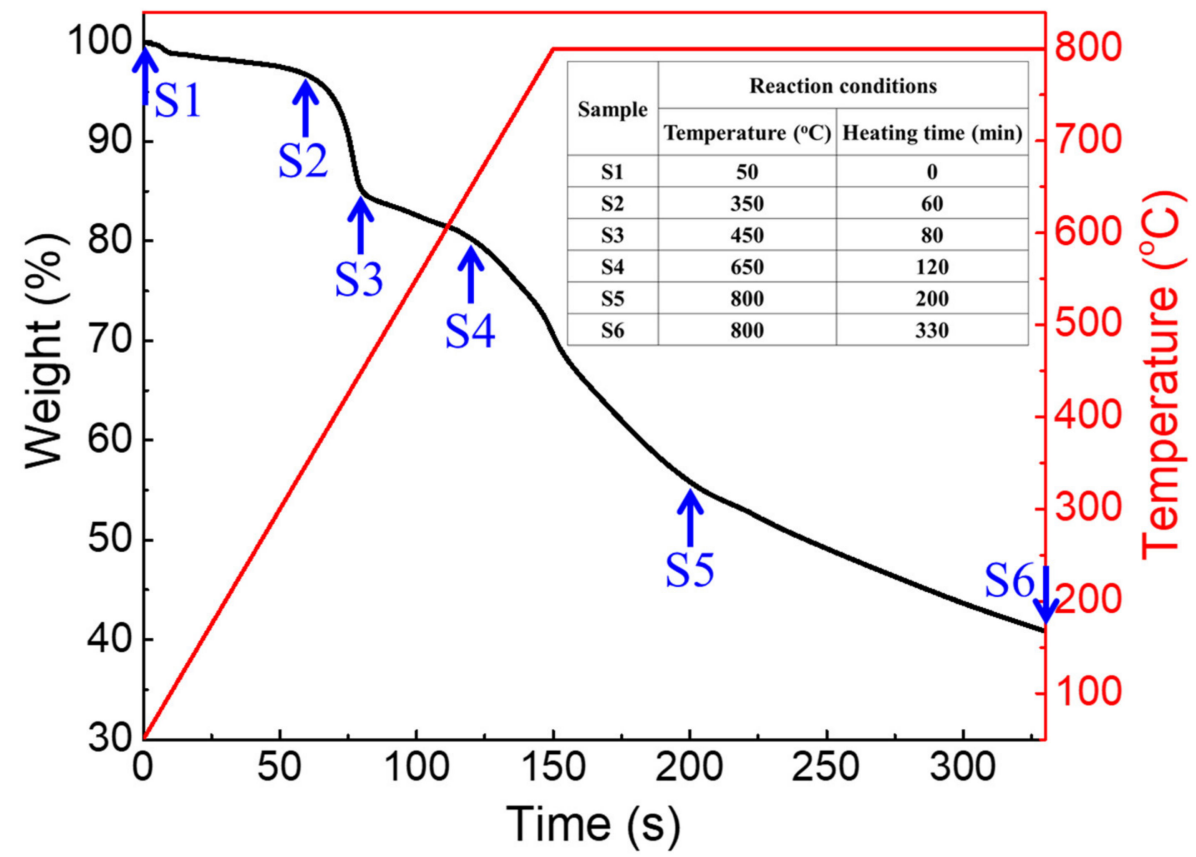

Figure 1. Mass loss performance of activation treatment process in TGA.

Table 1. The yields and specific capacitances at six stages.

\begin{tabular}{cccccc}
\hline \multirow{2}{*}{ Sample } & \multicolumn{2}{c}{ Product } & \multicolumn{3}{c}{ AWTC } \\
\cline { 2 - 6 } & Yield $_{\text {TGA }}$ & Yield $_{\text {furnace }}$ & Yield $_{\text {AWTC }}$ & Proportion & SC \\
\hline S1 & 100.0 & 100.0 & 75.4 & 22.1 & 0.2 \\
S2 & 96.7 & 95.0 & 71.7 & 22.1 & 0.8 \\
S3 & 85.1 & 82.3 & 41.6 & 14.8 & 5.3 \\
S4 & 80.2 & 81.7 & 32.8 & 11.8 & 12.4 \\
S5 & 55.8 & 61.5 & 22.6 & 10.7 & 62.8 \\
S6 & 40.9 & 43.7 & 21.0 & 14.1 & 112.5 \\
\hline
\end{tabular}

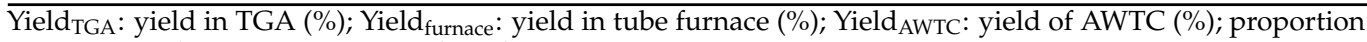
(\%); SC: specific capacitance at $1 \mathrm{~A} / \mathrm{g}(\mathrm{F} / \mathrm{g})$.

Incorporating with the products yields, AWTCs yields, and AWTCs proportions in products, the activation treatment process could be preliminarily understood: (1) S1-S2: Yield $_{\text {furnace }}$ and Yield ${ }_{\text {AWTC }}$ decrease $5.0 \% / 3.7 \%$ while AWTC proportion hardly changes, indicating that oxidation reaction slightly proceeds; (2) S2-S3: Yield furnace $_{\text {and }}$ Yield $\mathrm{AWTC}_{\mathrm{AT}}$ decrease $12.7 \% / 30.1 \%$ while AWTC proportion decreases $7.3 \%$, suggesting that the reaction strongly occurs when AWTC is obviously consumed with inorganic matter (IM) 
being partly decomposed; (3) S3-S4: Yield furnace $_{\text {and Yield }}$ AWTC decrease $0.6 \% / 8.8 \%$ while AWTC proportion decreases 3.0\%, revealing that AWTC partly converts to IM; (4) S4-S5: Yield $_{\text {furnace }}$ and Yield AWTC $_{\text {decrease }} 20.2 \% / 10.2 \%$ while AWTC proportion keeps nearly unchanged, telling that activation reaction strongly proceeds when AWTC and IM are simultaneously reacted; (5) S5-S6: Yield furnace $_{\text {and Yield }}$ AWTC decrease 17.8\%/1.6\% while AWTC proportion increases 3.4\%, reflecting that IM is massively decomposed.

Besides, from the detailed specific capacitance values, it can be clearly seen that the specific capacitances of AWTCs are $0.2 \mathrm{~F} / \mathrm{g}, 0.8 \mathrm{~F} / \mathrm{g}, 5.3 \mathrm{~F} / \mathrm{g}$, and $12.4 \mathrm{~F} / \mathrm{g}$ at S1, S2, S3, and S4 respectively. However, it would be obviously improved to $62.8 \mathrm{~F} / \mathrm{g}$ at S5, and further increased to $112.5 \mathrm{~F} / \mathrm{g}$ when the char undergoes heat treatment from S5 to S6. The phenomenon directly suggests that effective activation process occurs after $S 4\left(650{ }^{\circ} \mathrm{C}\right)$.

\subsection{Structural Evolution of Char during Activation Treatment Process}

\subsubsection{Evolution of Physical Structure}

The physical structure basically refers to textural properties, and they can be analyzed by specific surface area, pore volume, and average pore diameter [23]. Besides, according to the pore diameter, the pores can be divided into micropores $(<2 \mathrm{~nm})$, mesopores $(2-50 \mathrm{~nm})$, and macropores $(>50 \mathrm{~nm})$ [26]. In order to know the detailed textural properties evolution during activation treatment process, AWTCs were analyzed using a $\mathrm{N}_{2}$ adsorption-desorption analyzer and calculated with BET, t-plot, and BJH methods respectively [28], whose results are exhibited in Table 2.

Table 2. Textural properties of AWTCs at six stages.

\begin{tabular}{|c|c|c|c|c|c|c|c|c|}
\hline \multirow{2}{*}{ Sample } & \multicolumn{3}{|c|}{$\mathrm{SA}\left(\mathrm{m}^{2} / \mathrm{g}\right)$} & \multicolumn{3}{|c|}{$\mathrm{V}\left(\mathrm{cm}^{3} / \mathrm{g}\right)$} & \multicolumn{2}{|c|}{$D$ (nm) } \\
\hline & $S_{\text {BET }}$ & $\mathrm{S}_{\text {micro }}$ & $\mathrm{S}_{\text {meso+macro }}$ & $\mathrm{V}_{\text {total }}$ & $\mathrm{V}_{\text {micro }}$ & $\mathrm{V}_{\text {meso+macro }}$ & $\mathrm{D}_{\text {total }}$ & $\mathrm{D}_{\text {meso+macro }}$ \\
\hline S1 & 54.79 & $\mathrm{~N} / \mathrm{A}$ & 73.75 & 0.62 & $\mathrm{~N} / \mathrm{A}$ & 0.64 & 45.38 & 34.50 \\
\hline S2 & 56.57 & N/A & 74.92 & 0.58 & N/A & 0.60 & 41.31 & 31.90 \\
\hline S3 & 71.55 & N/A & 88.28 & 0.60 & N/A & 0.62 & 33.65 & 27.85 \\
\hline S4 & 69.59 & N/A & 84.99 & 0.58 & N/A & 0.59 & 33.11 & 27.65 \\
\hline S5 & 242.57 & 100.25 & 168.37 & 0.66 & 0.05 & 0.63 & 10.91 & 14.98 \\
\hline S6 & 207.53 & 68.01 & 167.97 & 0.58 & 0.04 & 0.56 & 11.19 & 13.42 \\
\hline
\end{tabular}

SA: specific surface area $\left(\mathrm{m}^{2} / \mathrm{g}\right)$; V: pore volume $\left(\mathrm{cm}^{3} / \mathrm{g}\right)$; D: average pore diameter $(\mathrm{nm}) ; \mathrm{S}_{\mathrm{BET}}$ : by the BET method; $\mathrm{S}_{\text {micro }}$ and $\mathrm{V}_{\text {micro }}$ : by the $\mathrm{t}$-plot method; $\mathrm{S}_{\text {meso+macro, }} \mathrm{V}_{\text {meso+macro, }}$ and $\mathrm{D}_{\text {meso+macro }}$ : by the $\mathrm{BJH}$ method.

Based on the textural property evolution at six stages, the whole activation treatment process can be generally divided into two typical processes because of their totally different characteristics. The first one is S1-S4, and the second is S4-S6 since the specific surface area is hugely improved from S4 to S6. In detail, from S1 to S4, it is obvious that there are nearly no micropores in AWTCs and the textural properties evolution tendencies of whole pores are consistent with mesopores+macropores no matter specific surface area, pore volume

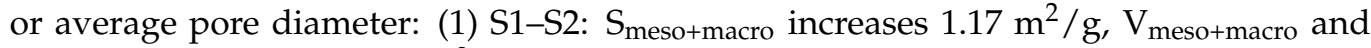
$\mathrm{D}_{\text {meso+macro }}$ decrease $0.04 \mathrm{~cm}^{3} / \mathrm{g}$ and $2.60 \mathrm{~nm}$ respectively, indicating that weak reaction and few smaller pores form; (2) S2-S3: $S_{\text {meso+macro }}$ and $V_{\text {meso+macro increase } 13.36 \mathrm{~m}^{2} / \mathrm{g} \text { and }}$

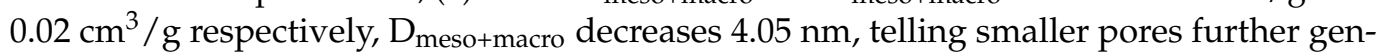

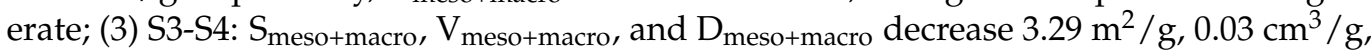
and $0.20 \mathrm{~nm}$ respectively, suggesting few char structures are slightly destroyed and smaller pores convert to larger. However, when the activation temperature is over $650{ }^{\circ} \mathrm{C}(\mathrm{S} 4)$, the pores including micropores and mesopores+macropores would all massively pro-

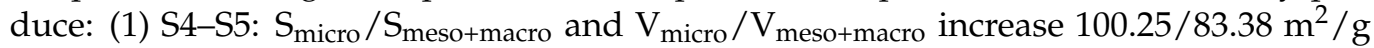
and $0.05 / 0.04 \mathrm{~cm}^{3} / \mathrm{g}$ respectively, while $\mathrm{D}_{\text {total }} / \mathrm{D}_{\text {meso+macro }}$ decrease $22.20 / 12.67 \mathrm{~nm}$, illustrating large quantities of pores generate and activation strongly proceeds; (2) S5-S6: $\mathrm{S}_{\text {micro }} / \mathrm{S}_{\text {meso+macro }}$ and $\mathrm{V}_{\text {micro }} / \mathrm{V}_{\text {meso+macro }}$ decrease $32.24 / 0.40 \mathrm{~m}^{2} / \mathrm{g}$ and $0.01 / 0.07 \mathrm{~cm}^{3} / \mathrm{g}$ respectively, while $D_{\text {total }}$ increases $0.28 \mathrm{~nm}$ and $D_{\text {meso+macro }}$ decreases $1.56 \mathrm{~nm}$, suggesting that smaller pores partly form to larger as for micropores, while larger pores fractionally convert to smaller for mesopores+macropores. Therefore, from the textural properties evolution, it can be found that during the whole activation treatment process, the effective 
activation only occurs when the temperature exceeds $650{ }^{\circ} \mathrm{C}$, which could verify the analysis results in our previous work [17]. In this situation, $\mathrm{K}_{2} \mathrm{FeO}_{4}$ would act as an activation agent and oxidize the char to generate more pores and improve specific surface area, thus obviously promoting the specific capacitance of product chars.

\subsubsection{Evolution of Carbon Skeleton Structure}

The first-order Raman spectrum $\left(800-1800 \mathrm{~cm}^{-1}\right)$ can effectively reflect carbon skeleton structures of carbon materials [29,30], and thus it was used to achieve characterization of AWTCs at six stages during the activation treatment process and their spectrums are shown in Figure 2a. It can be clearly seen that there are both two typical peaks, while their peak intensities are almost equal whatever for S1-S6, suggesting the graphitization degree has not be significantly improved with activation treatment process proceeding [31,32]. The phenomenon suggests that WTC is a kind of hard carbon that could not be easily graphitized to possess high graphitization degree. In order to further investigate carbon skeleton structures of AWTCs deeply, the Raman spectrums were deconvoluted into 10 peaks using the method in previous studies $[16,30,33]$.
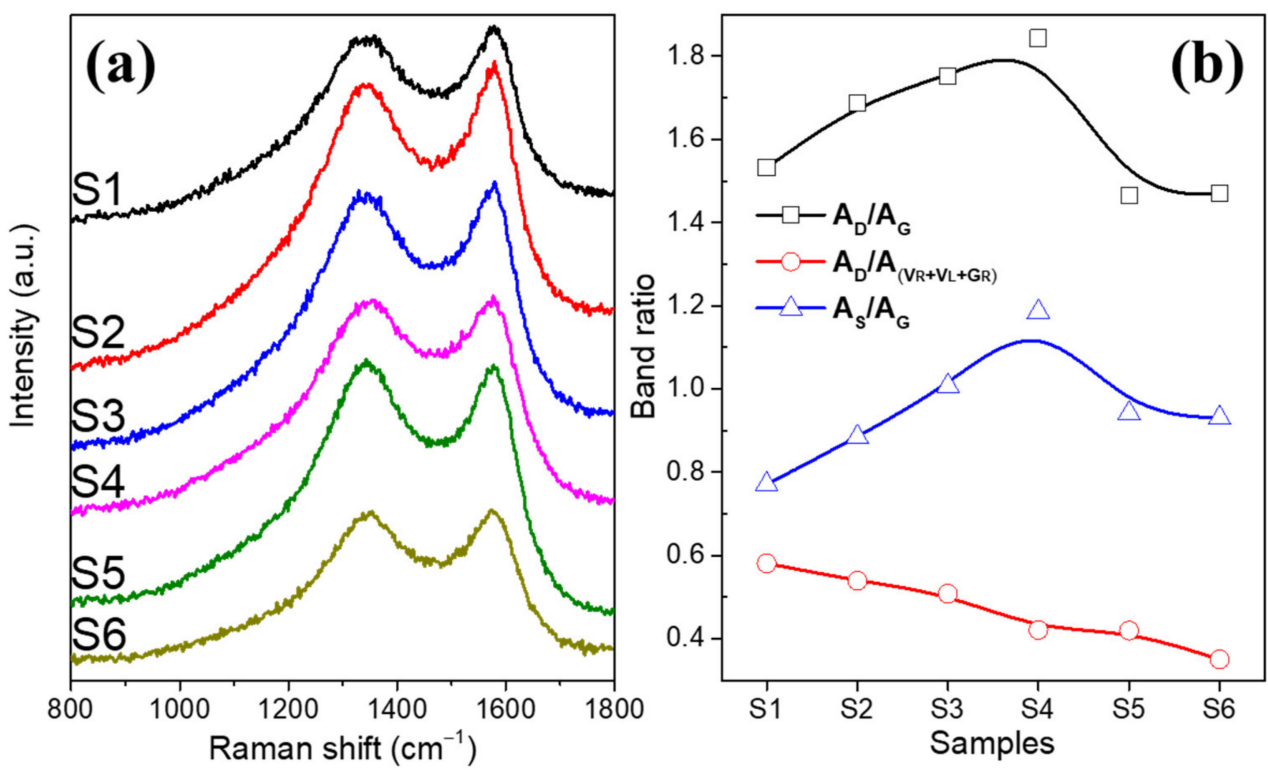

Figure 2. Raman spectrums (a) and their corresponding band area ratios (b) of AWTCs.

With the assistance of 10-peak method, the key band area ratios of $A_{D} / A_{G}, A_{D} /$ $A_{(V R+V L+G R)}, A_{S} / A_{G}$ of the chars at six stages were calculated and drawn in Figure $2 b$. From $A_{D} / A_{G}$ and $A_{S} / A_{G}$, it is clear that they take on two evolution characteristics during activation treatment process. When the char undergoes heat treatment from S1 to S4, $\mathrm{A}_{\mathrm{D}} / \mathrm{A}_{\mathrm{G}}$ and $\mathrm{A}_{\mathrm{S}} / \mathrm{A}_{\mathrm{G}}$ both gradually increase, it tells concentrations of aromatic ring systems having six or more fused benzene rings increase with alkyl-aryl $C-C$ bonds gradually forming. Besides, at the same time, $A_{D} / A_{(V R+V L+G R)}$ has been decreasing, indicating the decreased ratio of large aromatic ring systems ( $\geq 6$ rings) and small aromatic ring systems, which illustrates that generation of small aromatic ring systems from the increase extent compared with $A_{D} / A_{G}$. The phenomenon indicates that during this process, at higher temperature, many aliphatic chain structures decompose, recombine, and polymerize to form aromatic ring systems. This is consistent with the published work about the char chemical structure evolution of carbonization process [30]. However, as the char is constantly heat-treated (S4-S6), $A_{D} / A_{G}$ and $A_{S} / A_{G}$ both significantly decrease, it suggests that large aromatic ring systems ( $\geq 6$ rings) obviously decrease along with alkyl-aryl C-C bonds gradually decomposing. While $A_{D} / A_{(V R+V L+G R)}$ has still been decreasing, signaling consumption of small aromatic ring systems during the process. The variations of them indicate that aromatic char turns to be highly ordered. This is mainly caused by the 
catalytic graphitization of Fe pieces decomposed by $\mathrm{K}_{2} \mathrm{FeO}_{4}$ when the temperature exceeds $650{ }^{\circ} \mathrm{C}[21,34]$. Besides, the carbon skeleton structure changes are consistent with the characteristics during effective activation process [16]. Therefore, the Raman results in this section also verify the analysis of textural properties that whole activation treatment process consists of two typical processes, and further illustrate that they are carbonization process (S1-S4) and effective activation process (S4-S6) respectively.

In addition, the XPS spectrums of C 1s for AWTCs at six stages were deconvoluted into five peaks as Figure 3 a shows to further illustrate the carbon skeleton structure evolution during activation treatment process. Five peaks are $\mathrm{C}=\mathrm{C}$ at $284.8 \mathrm{eV}, \mathrm{C}-\mathrm{C}$ at $285.4 \mathrm{eV}, \mathrm{C}-\mathrm{O}$ and $\mathrm{C}-\mathrm{S}$ at $285.8 \mathrm{eV}, \mathrm{C}=\mathrm{O}$ at $286.6 \mathrm{eV}$, and $\mathrm{O}=\mathrm{C}-\mathrm{OH}$ at $288.8 \mathrm{eV}$, respectively [16,27], whose relative contents are drawn in Figure $3 \mathrm{~b}$. It is obviously shown that the element carbon mainly exists in the form of $\mathrm{C}=\mathrm{C}$ because their relative contents are highest, which suggests that AWTCs mainly hold highly ordered $\mathrm{sp}^{2}$ carbon skeleton structure [16]. Furthermore, incorporating with the element carbon contents, the absolute contents ( $\mathrm{w} \mathrm{t} \%$, absolute content $=$ element carbon content $\times$ relative content) can be acquired. The absolute content of $C=C$ would firstly decrease during S1-S4, this is because that carbon atoms would arrange to form more aromatic ring systems and alkyl-aryl C-C bonds during carbonization process, thus resulting in a more amorphous carbon structure. Subsequently, the absolute content of $\mathrm{C}=\mathrm{C}$ would increase after $\mathrm{S} 4$ and it is led by the phenomenon that aromatic ring systems and alkyl-aryl C-C bonds transform to be highly ordered with the help of activation agent, which is also consistent with Raman results above. Besides, the rest carbons exist as $\mathrm{C}-\mathrm{C}, \mathrm{C}-\mathrm{O} / \mathrm{S}, \mathrm{C}=\mathrm{O}$, and $\mathrm{O}=\mathrm{C}-\mathrm{OH}$, and most of them are mainly oxidized due to oxygen decomposed from $\mathrm{K}_{2} \mathrm{FeO}_{4}$.

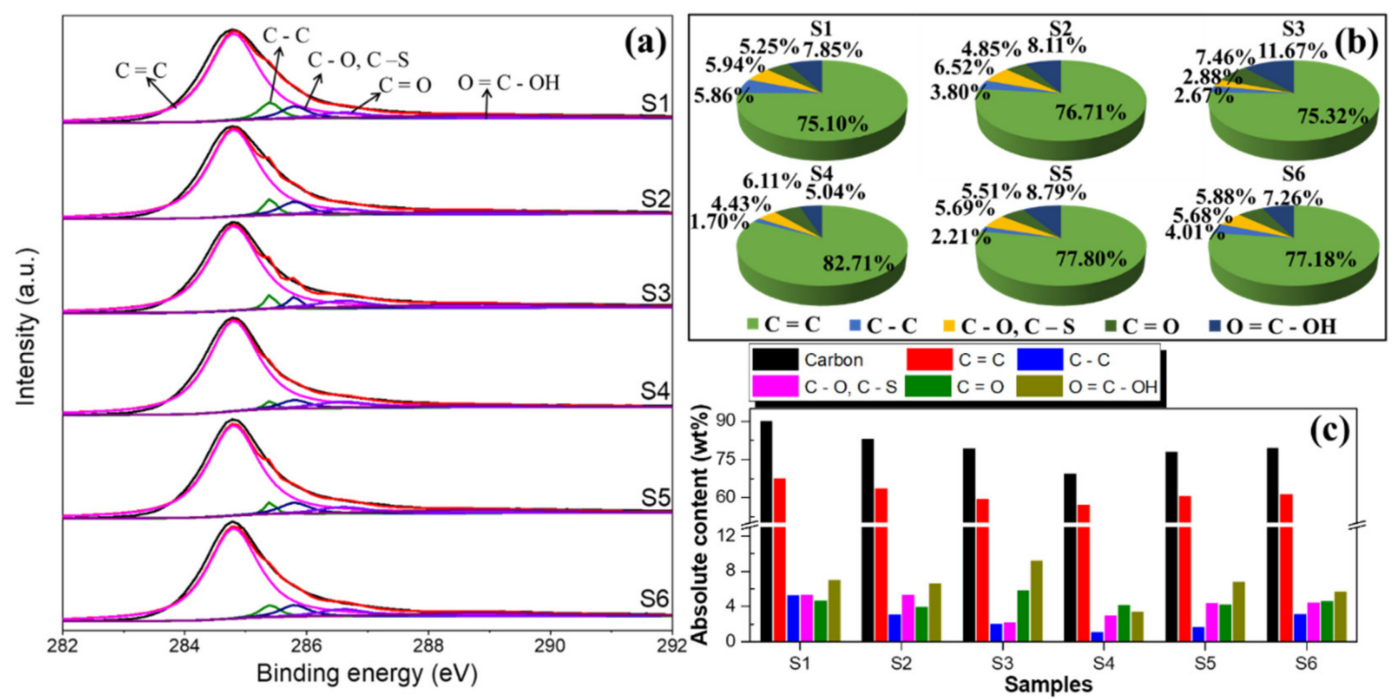

Figure 3. Deconvoluted XPS spectrums of C 1s into different chemical states for AWTCs (a), and their corresponding relative contents (b) and absolute contents (c).

\subsubsection{Evolution of Sulfur Doping Structure}

Except for the textural properties and carbon skeleton structure, sulfur doping structure is also key, by which some defects in carbon structures would generate and the physicochemical properties could be significantly improved $[35,36]$. Thus, this section would concentrate on deep investigations into sulfur doping structures for AWTCs at six typical stages. Figure 4a shows that element sulfur has been effectively doped into carbon skeleton structure and their characteristics are varied at different stages, because their $S 2 p$ spectrums are significantly distinct. Commonly, there are two sulfur pieces in the AWTCs and they are S 2 $\mathrm{p}_{3 / 2}\left(163.8-164.2 \mathrm{eV}\right.$ and 165.1-165.5 eV) and $\mathrm{S} 2 \mathrm{p}_{5 / 2}(168.6-169.1 \mathrm{eV}$ and $169.9-170.4 \mathrm{eV})$ respectively [16,27]. Further, the relative contents of two sulfur pieces are $85.78 \% / 14.22 \%, 78.26 \% / 21.74 \%, 67.07 \% / 32.93 \%, 42.42 \% / 57.58 \%, 48.43 \% / 51.57 \%$, and 
$53.13 \% / 46.87 \%$ at $\mathrm{S} 1-\mathrm{S} 6$ respectively. Incorporating with the element sulfur contents measured by EA, the absolute contents $(\mathrm{wt} \%$, absolute content $=$ element sulfur content $\times$ relative content) of two sulfur pieces can be calculated and shown in Figure $4 \mathrm{~b}$.
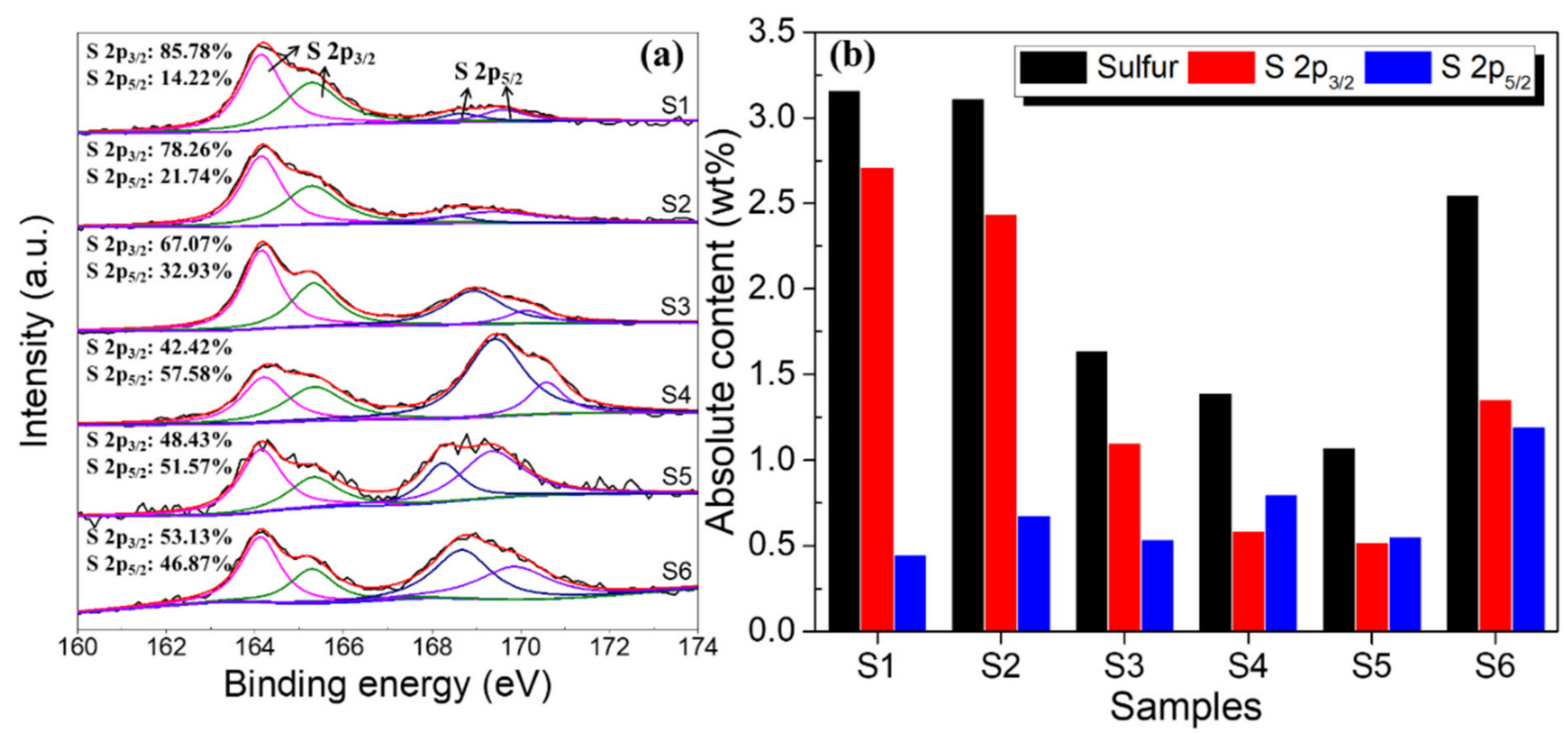

Figure 4. Deconvoluted XPS spectrums of S 2p into different chemical states for AWTCs (a), and their corresponding absolute contents (b).

It can be clearly seen that at $\mathrm{S} 1-\mathrm{S} 4$, the absolute content of $\mathrm{S} 2 \mathrm{p}_{3 / 2}$ would decrease from $2.71 \mathrm{wt} \%$ to $0.59 \mathrm{wt} \%$ with absolute content of $\mathrm{S} 2 \mathrm{p}_{5 / 2}$ taking on an increase tendency wholly, and corresponding relative content of $S 2 p_{3 / 2}$ has been decreasing with $S 2 p_{5 / 2}$ increasing. The phenomena suggests that huge consumption of $S 2 p_{3 / 2}$ with partial transformation of $\mathrm{S} 2 \mathrm{p}_{3 / 2}$ to $\mathrm{S} 2 \mathrm{p}_{5 / 2}$ during carbonization process, which can be inferred to be mainly led by the oxidation reactions on sulfur doping structure since $S 2 p_{5 / 2}$ possesses more oxygen atoms than $S 2 p_{3 / 2}$ from their chemical structures $[16,17,27]$.

However, $\mathrm{S} 2 \mathrm{p}_{3 / 2}$ then keeps almost unchanged from S4 to S5 since the contents are $0.59 \mathrm{wt} \%$ and $0.52 \mathrm{wt} \%$, and finally significantly increases to $1.35 \mathrm{wt} \%$ at $\mathrm{S} 6$. As for $\mathrm{S} 2 \mathrm{p}_{5 / 2}$, its absolute content has decreased slightly from S4 to S5 and obviously increases from 0.55 $\mathrm{wt} \%$ to $1.20 \mathrm{wt} \%$ (S6) subsequently. The results illustrate the enrichment of both $\mathrm{S} 2 \mathrm{p}_{3 / 2}$ and $\mathrm{S} 2 \mathrm{p}_{5 / 2}$ after $\mathrm{S} 5$ during effective activation process. Incorporating with AWTCs yields at S5 and S6 (nearly equal), it can be inferred that the enrichment of $S 2 p_{3 / 2}$ and $S 2 p_{5 / 2}$ can be resulted by their transformation from IM to AWTC like other inorganic salts $[37,38]$.

\subsection{Correlation Analysis of Structural Parameters and Specific Capacitance}

During activation treatment process, WTC is heat-treated when the physical/chemical structures and specific capacitance would evolve to be shown to researchers. Unexpectedly, the structural parameters are multitudinous and complex, causing serious obstacles in further understanding the effects of different structures on the specific capacitance during activation treatment process. In this section, the correlations between specific capacitance and diversiform structural parameters would be systematically discovered to comprehend the effects of various structures with Pearson's correlation analysis method. According to experimental results above, the specific capacitances are still nearly the equal at S1S4 (carbonization process), and only increase obviously from S4-S6 (effective activation process). Thus, as for correlation analysis, it can be inferred that the relevant errors would be big and seriously affect the conclusions during carbonization process. However, the specific values of specific capacitances during effective activation process are significantly and largely different from each other. Therefore, the relevant data are although not too many, but can be still representative. Thus, in order to understand the different roles of structures 
on specific capacitance, we firstly reasonably simplified the structural parameters and saved the independent parts. Then, Pearson's correlation coefficients (r) of diverse independent structural parameters with specific capacitance during effective activation process were calculated and shown in Table 3. Admittedly, the correlation effect extent can be expressed as 'strong', 'moderate', 'weak', and 'no' when the absolute values of $\mathrm{r}$ are $0.8-1.0,0.5-0.8$, $0.3-0.5$, and $0-0.3$, respectively, and the positive and negative effects on larger specific capacitance depend on whether the coefficients are positive or negative. In addition, from the specific values of corresponding $r$, the dominant factors for higher specific capacitance can be acquired. In detail, when $\mathrm{r}$ is positive and over 0.5 , the corresponding factor can be regarded as a dominant role in promoting specific capacitance. In addition, when $r$ is bigger, the factor is more dominant.

Table 3. Effects of structures on specific capacitance during effective activation process.

\begin{tabular}{cccccc}
\hline Parameter & $\mathbf{S}_{\text {micro }}$ & $\mathbf{S}_{\text {meso+macro }}$ & $\mathbf{V}_{\text {micro }}$ & $\mathbf{V}_{\text {meso+macro }}$ & D $_{\text {meso+macro }}$ \\
\hline $\begin{array}{c}\mathrm{r} \\
\text { Extent }\end{array}$ & $\begin{array}{c}0.67 \\
\text { moderate }\end{array}$ & $\begin{array}{c}0.87 \\
\text { strong }\end{array}$ & $\begin{array}{c}0.76 \\
\text { moderate }\end{array}$ & $\begin{array}{c}-0.42 \\
\text { weak }\end{array}$ & $\begin{array}{c}-0.91 \\
\text { strong }\end{array}$ \\
\hline Parameter & $\mathrm{A}_{\mathrm{D}} / \mathrm{A}_{\mathrm{G}}$ & $\mathrm{A}_{\mathrm{D}} / \mathrm{A}_{(\mathrm{VR}+\mathrm{VL}+\mathrm{GR})}$ & $\mathrm{A}_{\mathrm{S}} / \mathrm{A}_{\mathrm{G}}$ \\
\hline $\mathrm{r}$ & -0.86 & \multicolumn{2}{c}{-0.87} & -0.89 \\
Extent & strong & \multicolumn{2}{c}{ strong } \\
\hline Parameter & $\mathrm{S} 2 \mathrm{p}_{3 / 2}$ & $\mathrm{~S} 2 \mathrm{p}_{5 / 2}$ & strong \\
\hline $\mathrm{r}$ & 0.82 & \multicolumn{3}{c}{0.61} \\
Extent & strong & \multicolumn{3}{c}{ moderate } \\
\hline
\end{tabular}

According to the results in Table $3, \mathrm{~S}_{\text {meso+macro }}$ and $\mathrm{S} 2 \mathrm{p}_{3 / 2}$ are both strongly positive; $\mathrm{S}_{\text {micro }}, \mathrm{V}_{\text {micro, }}$ and $\mathrm{S} 2 \mathrm{p}_{5 / 2}$ are all moderately positive. Thus, it can be reasonably inferred that during effective activation process, $\mathrm{S}_{\text {micro }}, \mathrm{V}_{\text {micro }}, \mathrm{S}_{\text {meso+macro, }} \mathrm{S} 2 \mathrm{p}_{3 / 2}$, and $\mathrm{S} 2 \mathrm{p}_{5 / 2}$ all account for the huge improvement of specific capacitance. Further, these dominant 'strong' factors for larger specific capacitance obey the order: $S_{\text {meso+macro }}>S p_{3 / 2}>V_{\text {micro }}>S_{\text {micro }}$ $>\mathrm{S} 2 \mathrm{p}_{5 / 2}$. Focusing on the textural properties, it can be concluded that no matter micropores or mesopores+macropores can all promote specific capacitance. While the smaller pore diameter of mesopores+macropores possesses stronger promotion effect than micropores since $\mathrm{D}_{\text {meso+macro }}$ is strongly negative. The carbon skeleton structures are jointly described by $A_{D} / A_{G}, A_{D} / A_{(V R+V L+G R)}$, and $A_{S} / A_{G}$, all decreases of them indicate a more ordered $\mathrm{sp}^{2}$ graphitic carbon. In consideration of sulfur doping structure, doped sulfur composed by two sulfur pieces can both promote specific capacitance, and $S 2 p_{3 / 2}$ possessed stronger ability than $S 2 p_{5 / 2}$. It has been proved that larger specific surface, more ordered $\mathrm{sp}^{2}$ graphitic carbon, and higher sulfur doping content can all promote the specific capacitance of carbon material based on the published works $[21,34]$, which verifies the reasonability of the analysis results above. Besides, this work also takes on more specific information about improving specific capacitance than before.

Summarizations of waste tire char chemical treatment and their relevant specific capacitances are shown in Table 4 . It is clear that $\mathrm{K}_{2} \mathrm{FeO}_{4}$-assited activation of WTC in this work can help to achieve similar specific capacitance at lower activation agent content than published works $[12,39]$. Therefore, in order to further improve specific capacitance of AWTCs, the efficient activation agent should be firstly selected, then the activation treatment process can be adjusted, and the targets are as below: (1) larger specific surface area, mesopores+macropores possess stronger promotion effect than micropores; (2) more highly ordered $\mathrm{sp}^{2}$ carbon; (3) more doped sulfur- $\mathrm{S} 2 \mathrm{p}_{3 / 2}$ possesses stronger promotion effect than $S 2 \mathrm{p}_{5 / 2}$ 
Table 4. Summarizations of waste tire char chemical treatment and relevant results.

\begin{tabular}{cccc}
\hline Activation Agent and Content & Temperature & Specific Capacitance & Ref. \\
\hline $\mathrm{H}_{3} \mathrm{PO}_{4}\left(\mathrm{H}_{3} \mathrm{PO} 4 / \mathrm{WTC}=5\right)$ & $900{ }^{\circ} \mathrm{C}$ & $106.4 \mathrm{~F} / \mathrm{g}$ at $1 \mathrm{~A} / \mathrm{g}$ & {$[12]$} \\
$\mathrm{K}_{2} \mathrm{CO}_{3}\left(\mathrm{~K}_{2} \mathrm{CO}_{3} / \mathrm{WTC}=8\right)$ & $800{ }^{\circ} \mathrm{C}$ & $111.0 \mathrm{~F} / \mathrm{g}$ at $0.25 \mathrm{~A} / \mathrm{g}$ & {$[39]$} \\
\hline
\end{tabular}

The content represents the mass ratio of activation agent to waste tire char.

\section{Conclusions}

$\mathrm{K}_{2} \mathrm{FeO}_{4}$-assisted activation mechanisms of WTC were deeply revealed by operando experimental method successfully. The main conclusions were shown as below:

(1) The whole activation treatment process can be divided into six typical stages, and consisted of carbonization process (S1-S4) and effective activation process (S4-S6), the activation effect worked obviously after $650{ }^{\circ} \mathrm{C}$.

(2) During carbonization process: aromatic ring systems and alkyl-aryl C-C bonds generated; sulfur (mainly S 2 $p_{3 / 2}$ ) was gradually consumed. During effective activation process: aromatic ring systems and alkyl-aryl $\mathrm{C}-\mathrm{C}$ bonds turned to be graphitic ordered chars; pores massively produced from S4 to S5, and micropores partly formed to larger with mesopores+macropores fractionally converting to smaller from $\mathrm{S} 5$ to S6; sulfur transformed from IM to AWTC, leading to enrichments of $S 2 p_{3 / 2}$ and $S$ $2 p_{5 / 2}$ after $S 5$.

(3) The key structural parameters for huge improvement of specific capacitance were systematically found, it further revealed that mesopores+macropores possessed stronger promotion effect than micropores and $S 2 p_{3 / 2}$ was more beneficial than $S 2 p_{5 / 2}$.

Author Contributions: Conceptualization, L.J. and Q.R.; data curation, Q.R. and L.H.; formal analysis, Q.R. and Q.L.; funding acquisition, S.H.; investigation, Q.R. and Z.L.; project administration, S.H. and J.X.; supervision, S.H. and J.X.; validation. Q.H., S.S. and Y.W.; visualization, Q.R. and Z.L.; writing—original draft, Q.R.; writing—review and editing, S.H., Q.H., Q.L., L.H., S.S., Y.W., L.J. and J.X. All authors have read and agreed to the published version of the manuscript.

Funding: This research was financially supported by National Key R\&D Program of China (No. 2018YFE0127500).

Institutional Review Board Statement: Not applicable.

Informed Consent Statement: Not applicable.

Data Availability Statement: The data presented in this study are available on request from the corresponding author. The data are not publicly available due to data that forms part of an ongoing study.

Acknowledgments: The assistance from the Analytical and Testing Center of Huazhong University of Science and Technology is highly acknowledged. In addition, we also thank the facility support of the Equipment Center in State Key Laboratory of Coal Combustion, Huazhong University of Science and Technology.

Conflicts of Interest: The authors declare no conflict of interest.

\section{References}

1. Analysis of Current Situation of Global and Chinese Tire Market. Available online: http://www.tireworld.com.cn/data/reports/ specil/2018731/29870.html (accessed on 31 July 2018).

2. Martí, N.; Joaquim, R.; Jordi, D.F.; Marta, S.; José, L.D. Human exposure to environmental pollutants after a tire landfill in Spain: Health risks. Environ. Int. 2016, 97, 37-44.

3. Shakya, P.R.; Shrestha, P.; Tamrakar, C.S.; Bhattarai, P.K. Studies on potemtial emission of hazardous gases due to uncontrolled open-air burning of waste vehicle tyres and their possible impacts on the environment. Atmos. Environ. 2018, 42, 6555-6559. [CrossRef]

4. Chao, L.; Zhang, C.; Zhang, L.; Mortaza, G.; Hu, X. Catalytic pyrolysis of tire waste: Impacts of biochar catalyst on product evolution. Waste Manag. 2020, 116, 9-21. [CrossRef] [PubMed]

5. Deng, W.; Xu, K.; Xiong, Z.; Weerawut, C.; Wang, X.; Su, S. Evolution of aromatic structures during the low-temperature electrochemical upgrading of bio-oil. Energ. Fuel 2019, 33, 11292-11301. [CrossRef] 
6. Wang, C.; Tian, X.; Zhao, B.; Zhu, L.; Li, S. Experimental Study on Spent FCC Catalysts for the Catalytic Cracking Process of Waste Tires. Processes 2019, 7, 335. [CrossRef]

7. Xiong, Z.; Guo, J.; Weerawut, C.; Deng, W.; Hu, X.; Han, H. Assessing the chemical composition of heavy components in bio-oils from the pyrolysis of cellulose, hemicellulose and lignin at slow and fast heating rates. Fuel Process. Technol. 2020, 199, 106299. [CrossRef]

8. Williams, P.T. Pyrolysis of waste tyres: A review. Waste Manag. 2013, 33, 1714-1728. [CrossRef] [PubMed]

9. Li, L.; Liu, S.; Zhu, T. Application of activated carbon derived from scrap tires for adsorption of Rhodamine B. J. Environ. Sci. 2010, 22, 1273-1280. [CrossRef]

10. Faizan, A.; Mishmal, A.K.; Muhammad, A.Q.; Syyed, A.R.S.; Nasir, M.K.; Zia, K.; Hafiz, S.R.; Hunain, A.; Muhmmad, F.; Muhammad, W. Utilization of Pyrolytic Carbon Black Waste for the Development of Sustainable Materials. Processes 2020, 8, 174.

11. William, U.Y.; Natalia, C.U.; Carlos, A.V.I.; Juan, D.M. Incorporating the recovered carbon black produced in an industrial-scale waste tire pyrolysis plant into a natural rubber formulation. J. Environ. Manag. 2021, 287, 112292.

12. Zhi, M.; Yang, F.; Meng, F.; Li, M.; Manivannan, A.; Wu, N. Effects of pore structure on performance of an activated-carbon supercapacitor electrode recycled from scrap waste tires. ACS Sustain. Chem. Eng. 2014, 2, 1592-1598. [CrossRef]

13. Tang, L.; Huang, H. Thermal plasma pyrolysis of used tires for carbon black recovery. J. Mater. Sci. 2005, 40, 3817-3819. [CrossRef]

14. Xu, J.; Yu, J.; Xu, J.; Sun, C.; He, W.; Huang, J. High-value utilization of waste tires: A review with focus on modified carbon black from pyrolysis. Sci. Total Environ. 2020, 742, 140235. [CrossRef]

15. Ren, Q.; He, L.; Hu, S.; Su, S.; Wang, Y.; Jiang, L. The structural characteristics of waste tire chars at different pyrolysis temperatures. IOP Conf. Ser. Earth Environ. Sci. 2021, 657, 012005. [CrossRef]

16. Ren, Q.; Wu, Z.; Hu, S.; He, L.; Su, S.; Wang, Y. Sulfur self-doped char with high specific capacitance derived from waste tire: Effects of pyrolysis temperature. Sci. Total Environ. 2020, 741, 140193. [CrossRef]

17. Ren, Q.; Hu, S.; He, L.; Wu, F.; Wu, Z.; Lei, Z. Waste tire heat treatment to prepare sulfur self-doped char via pyrolysis and $\mathrm{K}_{2} \mathrm{FeO}_{4}$-assisted activation methods. Waste Manag. 2021, 125, 145-153. [CrossRef]

18. Hu, Y.; Liu, H.; Ke, Q.; Wang, J. Effects of nitrogen doping on supercapacitor performance of a mesoporous carbon electrode produced by a hydrothermal soft-templating process. J. Mater. Chem. A 2014, 2, 11753-11758. [CrossRef]

19. Soheila, F.; Farid, N.A. The development supercapacitor from activated carbon by electroless plating-A review. Renew. Sust. Energ. Rev. 2015, 42, 823-834.

20. Xie, K.; Qin, X.; Wang, X.; Wang, Y.; Tao, H.; Wu, Q. Carbon nanocages as supercapacitor electrode materials. Adv. Mater. 2012, 24, 347-352. [CrossRef]

21. Hou, L.; Hu, Z.; Wang, X.; Qiang, L.; Zhou, Y.; Lv, L. Hierarchically porous and heteroatom self-doped graphitic biomass carbon for supercapacitors. J. Colloid Interface Sci. 2019, 540, 88-96. [CrossRef]

22. Huang, X.; Gou, L.; Yang, L. Enhancement in performance of negative electrode of supercapacitor based on nitrogen doped porous sphere. J. Alloys Compds 2019, 786, 91-97. [CrossRef]

23. Cazetta, A.L.; Vargas, A.M.M.; Nogami, E.M.; Kunita, M.H.; Guilherme, M.R.; Martins, A.C. NaOH-activated carbon of high surface area produced from coconut shell: Kinetics and equilibrium studies from the methylene blue adsorption. Chem. Eng. J. 2011, 174, 117-125. [CrossRef]

24. Leila, K.; Mohammed, H.; Esmaeil, F. Adsorption of benzene and toluene from waste gas using activated carbon activated by $\mathrm{ZnCl}_{2}$. Front. Environ. Sci. Eng. 2014, 8, 835-844.

25. Nima, K.; Abdullah, R.M.; Maryam, M.; Mohammed, A.Z. Synthesis of vinasse-dolomite nanocomposite biochar via a novel developed functionalization method to recover phosphate as a potential fertilizer substitute. Front. Environ. Sci. Eng. 2020, 14, 70.

26. Zivica, V.; Palou, M.T. Physico-chemical characterization of thermally treated bentonite. Compos. Part B-Eng. 2015, 68, 436-445. [CrossRef]

27. Sevilla, M.; Fuertes, A.B. Highly porous S-doped carbons. Micropor. Mesopor. Mater. 2012, 158, 318-323. [CrossRef]

28. Carati, A.; Ferraris, G.; Guidotti, M.; Moretti, G.; Pasro, R.; Rizzo, C. Preparation and characterisation of mesoporous silica-alumina and silica-titania with a narrow pore size distuibution. Catal. Today 2003, 77, 315-323. [CrossRef]

29. Hu, C.; Sedghi, S.; Ana, S.A.; Andersson, G.G.; Sharma, A.; Pendleton, P. Raman spectroscopy study of the transformation of the carbonaceous skeleton of a polymer-based nanoporous carbon along the thermal annealing pathway. Carbon 2015, 85, 147-158. [CrossRef]

30. Li, X.; Hayashi, J.; Li, C. FT-Raman spectroscopic study of the evolution of char structure during the pyrolysis of a Victorian brown coal. Fuel 2006, 85, 1700-1707. [CrossRef]

31. He, L.; Liao, G.; Hu, S.; Jiang, L.; Han, H.; Li, H. Effect of temperature on multiple competitive processes for co-production of carbon nanotubes and hydrogen catalytic reforming of toluene. Fuel 2020, 264, 116749. [CrossRef]

32. Ren, Q.; He, L.; Hu, S.; Li, H.; Li, S.; Deng, Z. Formation of highly graphitic char derived from phenolic resin carbonization by Ni-Zn-B alloy. Environ. Sci. Pollut. Res. 2020, 27, 22639-22647. [CrossRef] [PubMed]

33. Chen, Y.; Syed, S.A.S.; Xiong, Z.; Li, Q.; Hu, X.; Xu, J. Temporal and spatial evolution of biochar chemical structure during biomass pellet pyrolysis from the insights of micro-Raman spectroscopy. Fuel Process. Technol. 2021, 218, 106839. [CrossRef]

34. Gong, Y.; Li, D.; Luo, C.; Fu, Q.; Pan, C. Highly porous graphitic biomass carbon as advanced electrode materials for supercapacitors. Green Chem. 2017, 19, 4132-4140. [CrossRef] 
35. Chen, W.; Wan, M.; Liu, Q.; Xiong, X.; Yu, F.; Huang, Y. Heteroatom-Doped Carbon Materials: Synthesis, Mechanism, and Application for Sodium-Ion Batteries. Small Methods 2019, 3, 1-18. [CrossRef]

36. Wang, X.; Sun, G.; Routh, P.; Kim, D.H.; Huang, W.; Chen, P. Heteroatom-doped graphene materials: Syntheses, properties and application. Chem. Soc. Rev. 2014, 43, 7067-7098. [CrossRef]

37. Ma, F.; Ma, D.; Wu, G.; Geng, W.; Shao, J.; Song, S. Construction of 3D nanostrcuture hierarchical porous graphitic carbons by charge-induced self-assembly and nanocrystal-assisted catalytic graphitization for supercapacitors. Chem. Commun. 2016, 52, 6673-6676. [CrossRef]

38. Suyeon, H.; Byungrak, S.; Hasuck, K.; Jakkid, S.; Sangaraju, S. The synergistic effect of nickel cobalt sulfide nanoflakes and sulfur-doped porous carboneous nanostructure as bifunctional electrocatalyst for enhanced rechargeable $\mathrm{Li}-\mathrm{O}_{2}$ batteries. Appl. Catal B-Environ. 2020, 263, 118283.

39. Bello, A.; Momodu, D.Y.; Madito, M.J.; Makgopa, K.; Rambau, K.M.; Dangbegnon, J.K. Influence of $\mathrm{K}_{3} \mathrm{Fe}(\mathrm{CN})_{6}$ on the electrochemical performance of carbon derived from waste tyres by $\mathrm{K}_{2} \mathrm{CO}_{3}$ activation. Mater. Chem. Phys. 2018, 209, 262-270. [CrossRef] 